\title{
Ivo Alexandre Hümmelgen, March 26, 1963-March 1, 2019
}

\section{Fritz Scholz ${ }^{1}$}

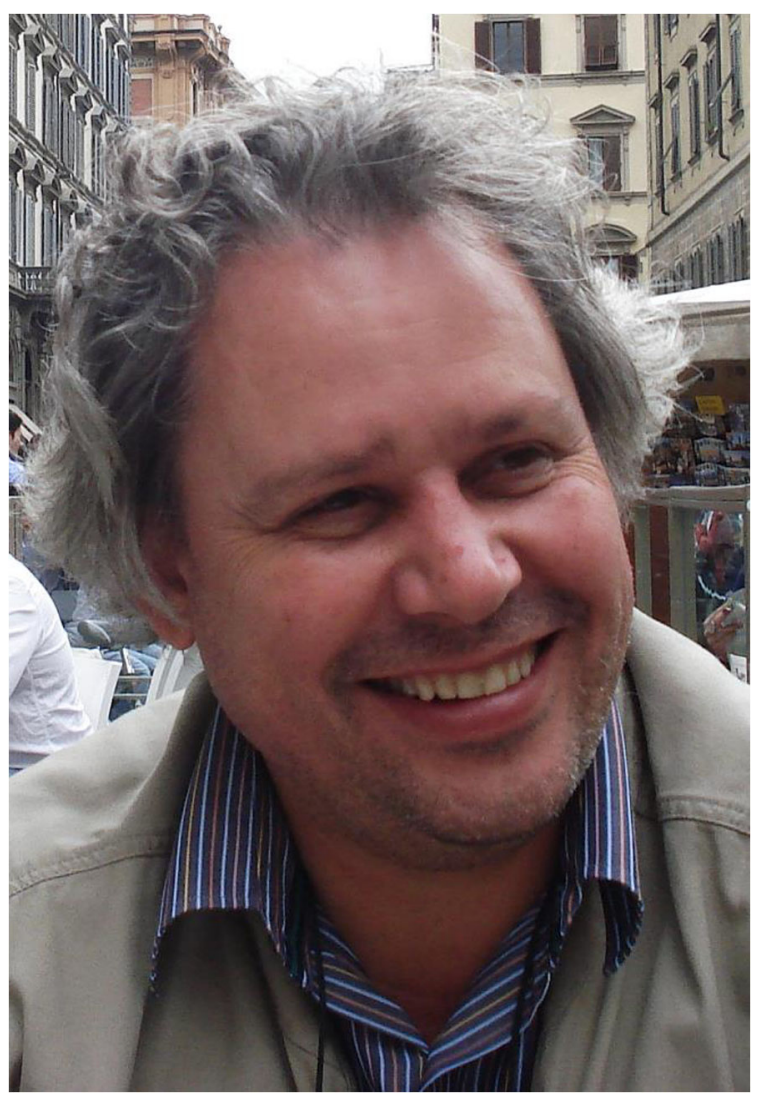

(Photo: courtesy of Michelle Sostag Meruvia)
In deep sorrow, we mourn the passing away of Ivo Alexandre Hümmelgen, our Topical Editor for photoelectrochemistry and semiconductor electrochemistry. Ivo has served our journal with great enthusiasm and dedication since 2006. The scientific community will miss him as scientist, colleague, editor, and friend.

We will publish a memorial issue and invite all his friends and colleagues to submit a manuscript dedicated to Ivo.

Publisher's note Springer Nature remains neutral with regard to jurisdictional claims in published maps and institutional affiliations.

Fritz Scholz

fscholz@uni-greifswald.de

1 Universität Greifswald, Institut für Biochemie, 17489 Greifswald, Germany 